their dependency on remuneration from the State.

Theoretically, present maximum part-time contract holders would marginally increase their share of remuneration from the State in the change from the present fraction of $9 / 11$ to one of $13 / 15$ but, if the Review Body were to meet the full aspirations of the negotiators and accept 10 sessions as the equivalent of a wholetime salary, the change would not be so small.

Mr Bolt quotes as the single most important feature of the new contract the fact that it "offers consultants the right to seek remuneration outside the State service, without loss of any part of the salary which they have earned within it." I am sure that present full-time consultants would like to hear the evidence from which they may reasonably anticipate that the opening to private earnings will be for them both significant and attainable. Do substantial opportunities, which are not already taken up, exist across the regions and across the spread of specialties? If the answer is doubtful our negotiators must not count on widespread support, and the idea of a shift in the balance of earning away from State dependency becomes equally questionable.

The greatest strength to carry into negotiation with Government would come from a consultant body united in its purpose; but study of these correspondence columns alone shows how far the proposed contract change has served to sharpen the division in the consultant ranks.

JOHN LEOPOLD

Department of Pathology, Welsh National School of Medicine, Cardiff CF4 4XN

' Central Committee for Hospital Medical Services Annual Report 1978-79. London, BMA, 1979.

\section{Clinical medical officers}

SIR,-I write to support the view of the presidents of the Royal Colleges of Physicians and the British Paediatric Association and the chairman of the Joint Paediatric Committee (12 May, p 1279) that the natural affiliation of most clinical medical officers "lies not with community medicine but with clinical paediatrics." This has been the expressed view of my faculty from our beginning. We emphasise our abiding concern for the future of the child health service and acknowledge warmly our historical responsibility towards our clinical medical officer colleagues, who must have the same entitlement to appropriate vocational training and professional advancement in their chosen field as other branches of the medical profession.

Specialists in community medicine will, of course, continue to have an important role in the child health services in determining need and facilitating the work of these services in the community.

JOHN BROTHERSTON President, Faculty of
Community Medicine of the Royal College of Physicians
of the United Kingdom

London NW1 4LE

SIR,-We welcome the recent correspondence in your colums on the functions, training, and career structure of the clinical medical officers. Our two associations share the belief that the majority of clinical medical officers are specialist clinicians working in the field of child health who wish to become more closely related to the appropriate paediatric clinical department, thereby loosening their traditional ties with community medicine.

We reject the recommendations of the Preston Working Party (17 February, p 503) which attempt to maintain the clinical medical officers in a generic community medicine role and do not recognise that these doctors are clearly and properly clinical doctors working in the field of child health.

ANNe M Jepson Chairman, Association of Specialists in Community

London NW6

SHELAGH TYRREL Chairman, Association of

Sutton, Surrey

\section{New GP Charter}

SIR,-In the report of the GP Charter Working Group (24 February, p 564) the items of service in their seven bands draw attention to themselves by having been set out in a list. This draws attention away from the manpower sections, which contain the aim to reduce maximum list size to 2000 . Here, surely, lies an answer to the problems set out by Dr B Jarman and Margaret Lally (17 March, p 757), where patients in an "overdoctored" area cannot get on the list of a GP. It also provides the space in a doctor's day to take on the extra tasks the DHSS pays lip service to by transferring some patient care from hospital to community.

With reduced list size must go raising of capitation fees in order to keep up income. Moreover, more committed new GPs will be able to break into inner urban areas, at a time when revenue to the hospitals there is being reduced.

Sir, I have spoken with enthusiastic GPs and I do find them here in inner urban Kensington, Chelsea, and Westminster as well as, for example, in Wallingford. We do not need bribery to answer extra needs of our patients. With a list size that allows us time to do this, it is enough that the capitation gives us an adequate income. I want nothing of the forms required for the 52 items of service, to say nothing of the fees for service.

R STONE

London W2 4LD

\section{Medical reports and confidentiality}

SIR, - We should like to raise again the matter of "medical attendants' reports," as we feel very strongly that they are both unethical and unnecessary. They clearly contravene the principle of confidentiality, which is an essential part of the relationship between a doctor and his patient.

Although patients have given their consent to the release of information from their records, there is little doubt that they feel obliged to do so. Moreover, it is unlikely (and we have confirmed this view by asking some of those involved) that they realise that the questionnaires require the release of information which they would, rightly, have regarded as confidential. The Life Offices are, in effect, demanding a security leak as a prerequisite to conducting their normal business.

In other sections of the business world risks are assessed by experience and a knowledge of the market, and when deals are made with the aid of leaked information they are frowned on. How much more should this be the case when the information concerned has originally been accepted by a doctor in the strictest confidence. There is a perfectly satisfactory alternative to the use of medical attendants' reports in the form of a medical history and examination by an independent doctor, which would involve no breach of confidence.

We cannot understand why the Life Offices should be treated as a special case in this way, or how the BMA came to reach its agreement with them, which at the very least condones the release of information and which we believe should be rescinded. The "agreement" is often referred to on the forms requesting information, and its very existence implies that the Life Offices have the authority of the BMA to seek it. This in turn makes it difficult, and occasionally almost impossible, to refuse to disclose it. This situation is deplorable.

The view of the Life Offices that they need and therefore must have this information can only have grown up because they have for some time been allowed to obtain it; but their need for the information is irrelevant to the central question of whether or not patients' records are confidential. There is no doubt that had they never been allowed this confidential information (which they should not have been) they would by now somehow have found a way to manage without it

It is difficult to fight this at a local level, since some of the companies concerned claim that it is "impossible" to offer a life policy (and in one instance even to offer employment) to a patient who is not willing to allow the release of confidential information from his records. The doctor who attempts to withhold it is then also involved in the "blackmail" by the obligatory personal intervention of the patient, asking him to comply with the company's wishes.

We feel that what is badly needed is a clear statement from the BMA to the effect that it deprecates the release of information from the medical records of patients, except to those involved directly in their medical care, whatever the fee offered. In this way the doctor might feel that he, rather than the Life Offices, had the authority of the BMA behind him.

G B MaY

Guildford, Surrey

W P GaRSON

\section{Points}

\section{The case against neonatal circumcision}

Dr J Slome (London W1) writes:... A ... factor that has made circumcision more difficult to understand, and therefore perform successfully, is the absence in most anatomy and surgical textbooks of a clear diagram illustrating how the skin layers are situated around the uncircumcised penis. The $10 \%$ of babies referred to in your leading article ( 5 May, $p$ 1163) as needing a second circumcision because of inadequate removal of mucosa, causing later a secondary phimosis, will be the result of this omission. Furthermore, to delay doing circumcisions until 3-5 years of age, as you advocated, will bring into play another group of complications, arising from the general anaesthetic that will now be required: babies up to about 6 months require no anaesthetic.

Dr Sula WolfF (Department of Psychological Medicine, Royal Hospital for Sick Children, 